\title{
Efficacies of uterine artery embolization for symptomatic uterine fibroids using gelatin sponge: a single-center experience and literature review
}

This article was published in the following Dove Press journal:

International Journal of Women's Health

12 August 2016

Number of times this article has been viewed

\section{Aska Toda' \\ Kenjiro Sawada' \\ Keigo Osuga ${ }^{2}$ \\ Noboru Maeda ${ }^{2}$ \\ Hiroki Higashihara ${ }^{2}$ \\ Tomoyuki Sasano' \\ Noriyuki Tomiyama \\ Tadashi Kimura' \\ 'Department of Obstetrics and Gynecology, ${ }^{2}$ Department of Diagnostic and Interventional Radiology, Osaka University Graduate School of Medicine, Osaka, Japan}

Correspondence: Kenjiro Sawada Department of Obstetrics and Gynecology, Osaka University Graduate School of Medicine, 2-2, Yamadaoka Suita, Osaka 565-087I, Japan

$\mathrm{Tel}+8 \mathrm{I} 66879335$ I

Fax +8I 668793359

Email daasawada@gyne.med.osaka-u.ac.jp
Aim: The aim of this study was to retrospectively analyze the efficacies of uterine artery embolization (UAE) using gelatin sponge for symptomatic uterine fibroids.

Methods: A series of 60 consecutive premenopausal women underwent UAE using gelatin sponge particles or porous gelatin particles. Patients were routinely followed up at 1, 3, 6, and 12 months after the procedure and asked to report any procedure-related complications. At each follow-up, an original clinical questionnaire was completed by the patients to evaluate changes in fibroid-related symptoms. Pelvic magnetic resonance imaging was performed before and at 3 and 12 months after the procedure, and the changes in volume of the dominant fibroid were calculated.

Results: Bilateral UAE was successfully performed in all the patients. Median age was 45 years (range 34-53 years), and median follow-up period was 25.2 months (range 1-116 months). At the 3- and 12-month follow-up, the dominant fibroid volumes were found to be significantly decreased by $33.4 \%$ (95\% confidence interval [CI]: 24.9-41.1) and 48.4\% (95\% CI: 40.7-56.1) compared to baseline volumes, respectively. Excluding patients not having menorrhagia or bulk-related symptoms, at 12 months 49 of 50 (98\%) women showed improvement in menorrhagia, and 45 of 47 (95.7\%) women showed improvement in bulk-related symptoms. During the follow-up period, ten patients $(16.7 \%)$ required further interventions including two patients who had undergone hysterectomy. No sequelae were experienced by any of the patients.

Conclusion: UAE using gelatin sponge was associated with a high clinical success rate and good fibroid volume reduction compared to UAE using other embolic agents.

Keywords: embolic agent, gelatin sponge, uterine artery embolization, uterine fibroid

\section{Introduction}

Uterine fibroids are the most common female pelvic tumors, typically reported to occur in $20 \%-40 \%$ of women of reproductive age. Nearly half of women with fibroids have significant symptoms such as heavy menstrual bleeding, menorrhagia, or intolerable pelvic pain. ${ }^{1}$ While symptomatic fibroids have been managed traditionally by myomectomy or hysterectomy using laparotomy or laparoscopy, uterine artery embolization (UAE), a minimally invasive vascular radiologic technique, has gradually gained popularity as an alternative to surgery, particularly hysterectomy. ${ }^{2}$ There are several advantages of UAE over other treatments including its less invasive nature, established favorable cost profile, and associated rapid recovery with most women being back to work within 2 weeks. ${ }^{3}$ Moreover, in various groups of patients, such as those with prior pelvic surgery, including myomectomy, as well as inflammatory conditions, prior radiation therapy, and other interventions, UAE is likely to be a safer option than 
surgery. ${ }^{4}$ Thus, nowadays, UAE is considered as one of the frontline therapies for uterine fibroids. Indeed, the American College of Obstetrics and Gynecology recently commented that "UAE is a safe and effective option for appropriate selected women who wish to retain their uterus, based on good and consistent scientific evidence". 5

While several randomized clinical trials have established robust evidence for UAE as an alternative to surgery, ${ }^{6}$ in these clinical trials, either Tris-acryl gelatin microspheres (TAGMs) (Embosphere; Merit Medical Systems Inc., South Jordan, UT, USA) or nonspherical polyvinyl alcohol (nPVA) particles were used. It was concluded that these agents were preferred for UAE in light of both clinical and imaging outcomes. ${ }^{7}$ However, in Japan, these embolic agents were not commercially available until 2014, and gelatin sponge particles cut from sheets or porous gelatin particle (PGP), a roughly calibrated embolic agent made of gelatin sponge, have been used for UAE. ${ }^{8}$ While several articles have shown that the outcomes of UAE using gelatin sponge were comparable to those of UAE using other embolic agents, ${ }^{8-10}$ these reports were single-institutional studies, and further accumulation of clinical evidence is warranted. With this in mind, we retrospectively analyzed our 10-year experience of UAE with gelatin sponge particles and PGP and assessed the long-term clinical outcomes alongside a literature review.

\section{Materials and methods \\ Patients}

Between January 2003 and December 2013, a total of 60 consecutive premenopausal women underwent UAE using gelatin sponge particles or PGP for symptomatic uterine fibroids. Patients were eligible if they had at least one symptom caused by uterine fibroids, such as menorrhagia, pain, or bulk-related symptoms that were difficult to manage by medication alone; they strongly wished to retain their uterus and avoid surgery, or they had serious comorbidities leading to difficulties in surgery. Exclusion criteria included the following: pregnancy, nursing, or desire for future pregnancy; active inflammatory disease; pelvic malignancy; contraindication to magnetic resonance imaging (MRI); or severe allergy to iodinated contrast media. The tumors were diagnosed as uterine fibroids by transvaginal ultrasound scope or enhanced pelvic MRI by experienced gynecologists. Pap smear was confirmed to be negative in all patients before the procedure. Upper limits on the volume of the uterine fibroids and uterus were not set. All patients were informed of the potential benefits and risks of UAE for uterine fibroids and provided written informed consent for the procedure. Patients' clinical information was obtained by retrospective review of medical records.

\section{Procedures}

UAE was performed during a short hospital stay, and hospitalization was planned to be a three-night stay after the procedure. Briefly, access to the femoral artery was achieved unilaterally, and an arteriogram using a 4 Fr pigtail catheter was performed to visualize the pelvic vasculature, particularly for the identification of the uterine artery, its origin, and any anatomic variations. Bilateral super-selective catheterization of both uterine arteries was subsequently achieved by the coaxial technique using a 4 Fr Mohri catheter (Hanaco Medical, Saitama, Japan) and a 2.4 Fr microcatheter (Masters HF; Asahi Intecc J-sales, Tokyo, Japan). Embolization was carried out using gelatin sponge particles (Spongel; Astellas, Tokyo, Japan) between 2003 and 2007, and thereafter using PGP (Gelpart; Nippon Kayaku, Tokyo, Japan) as the embolic agent. Gelatin sponge particles were provided in a form of sheet and cut into $1 \mathrm{~mm}$ cubes with a scalpel and scissors. PGP was provided in a ready-to-use vial as 1 and $2 \mathrm{~mm}$ particles. The procedure was continued until the proximal ascending uterine artery was nearly occluded and the main descending uterine arteries were patent under fluoroscopy. Thereafter, the contralateral uterine artery was similarly embolized. During the study period, one qualified radiologist (KO) performed and supervised these procedures. Peri- and post procedural pain was managed by intravenous infusions of fentanyl citrate using a syringe infusion pump. In all cases, patients were administered prophylactic intravenous antibiotics (cefazolin sodium $1 \mathrm{~g}$ ) before and 3 hours after the procedure, and a total dosage of $15 \mathrm{mg}$ prochlorperazine was prescribed orally in three separate doses for 4 days.

\section{Follow-up}

Patients were routinely followed up at 1, 3, 6, and 12 months after the procedure and were asked to report any adverse events. Gynecological examination and transvaginal ultrasound scopic analysis were performed at each visit to confirm the presence of any procedure-related complications. Patients underwent pelvic unenhanced and enhanced MRI before and at 3 and 12 months after UAE. The volume of the dominant fibroid was determined according to the method described by Janik et al, ${ }^{11}$ where length was the largest axis and width was the measured at right angle to the length:

$$
\text { Volume }=\text { Length } \times \text { Width }^{2} \times 0.5236
$$

In addition, the location of the dominant fibroid and the number of fibroids were recorded. The images obtained from all MRI examinations were interpreted by a qualified independent radiologist. 


\section{Outcome measurement}

An original clinical questionnaire was completed by patients before therapy and at the time of each follow-up ( 3 and 12 months after UAE) to evaluate changes in fibroid-related symptoms compared with baseline status. This questionnaire comprised assessment of changes in fibroid-related symptoms (general condition, menstruation, pain, and bulk-related complaints), satisfaction with outcome, and recommendation to a friend. Changes in fibroid-related symptoms were classified as follows: markedly improved, moderately improved, slightly improved, unchanged, and worsened compared with preprocedural symptoms. Patient satisfaction with the outcomes was classified as follows: greatly satisfied, moderately satisfied, slightly satisfied, not satisfied, and dissatisfied.

Complications were defined when patients underwent any additional interventions or treatments due to fibroid-related symptoms, including failure of symptom control and development of complication-related symptoms.

\section{Statistical analysis}

JMP version 10.0.2 (SAS Institute Inc., Cary, NC, USA) was used for statistical analyses. Differences were analyzed using Student's $t$-test and were considered statistically significant at $P<0.05$.

\section{Ethical approval}

All procedures performed in the study involving human participants were in accordance with the ethical standards of the institutional and/or national research committee and with the 1964 Declaration of Helsinki and its later amendments or comparable ethical standards. This retrospective study was approved by the Ethics Committees of Osaka University Graduate School of Medicine (No 15490). Patient consent was not required for this type of study.

\section{Results}

During the study period, 60 women underwent UAE: 29 with gelatin sponge particles and 31 with PGP. Bilateral UAE was technically successful in all patients without any procedural complications. Baseline characteristics of the patients are summarized in Table 1. Median age was 45 years (range 34-53 years), and median follow-up period was 25.2 months (range 1-116 months). The main symptoms that led to embolization were menorrhagia $(n=48)$, bulk-related symptoms $(n=41)$, and pelvic pain $(n=11)$. Fifty of $60(83.3 \%)$ women had multiple fibroids, and in 50 of $60(83.3 \%)$ patients, intramural fibroids were dominant. There were no significant differences between the patients who underwent UAE with gelatin sponge particles and those with PGP except for the follow-up period.

\section{Clinical outcomes}

Of the 60 patients who underwent UAE, the follow-up questionnaire responses were available for 56 patients $(93.3 \%)$ at 12 months after UAE. Questionnaire responses were not available for two patients who were lost to follow-up, and

Table I Baseline characteristics

\begin{tabular}{|c|c|c|c|}
\hline Baseline characteristics & Total $(n=60)$ & GSP $(n=29)$ & PGP $(n=31)$ \\
\hline Age, years, median (range) & $45(34-53)$ & $46(34-50)$ & $45(39-53)$ \\
\hline Follow-up period, days, median (range) & $757(44-3,491)$ & $940(2 \mid 9-3,491)$ & $40 I(44-I, 345)$ \\
\hline \multicolumn{4}{|l|}{ Presenting symptoms } \\
\hline Menorrhagia, $\mathrm{n}(\%)$ & $48(80.0)$ & $22(75.9)$ & $26(83.9)$ \\
\hline Dysmenorrhea, n (\%) & II (I8.3) & $4(13.8)$ & $7(22.6)$ \\
\hline Bulk-related symptoms, n (\%) & $4 I(68.3)$ & $21(72.4)$ & $20(64.5)$ \\
\hline \multicolumn{4}{|l|}{ Number of fibroids } \\
\hline I, n (\%) & $10(16.6)$ & $5(17.2)$ & $5(16.1)$ \\
\hline$>I, n(\%)$ & $50(83.3)$ & $24(6.2)$ & $26(83.9)$ \\
\hline \multicolumn{4}{|l|}{ Dominant fibroid location } \\
\hline Intramural, n (\%) & $50(83.3)$ & $26(89.7)$ & $24(77.4)$ \\
\hline Submucosal, n (\%) & $7(11.6)$ & $2(6.9)$ & $5(16.1)$ \\
\hline Subserosal, n (\%) & $3(5.0)$ & I (3.4) & $2(6.5)$ \\
\hline Dominant fibroid maximum diameter, $\mathrm{mm}$, median (range) & $88.5(35-240)$ & $89(35-123)$ & $88(51-240)$ \\
\hline Dominant fibroid volume, mL, median (range) & $214.6(10.6-5,026.6)$ & $222(10.6-974)$ & $199(51.7-5,026.6)$ \\
\hline \multicolumn{4}{|l|}{ Previous treatment } \\
\hline Myomectomy, n (\%) & II (I8.3) & $5(17.2)$ & $6(19.4)$ \\
\hline UAE, n (\%) & $4(6.7)$ & $3(10.3)$ & $\mathrm{I}(3.2)$ \\
\hline Hormonal therapy (OCs, GnRH agonists), n (\%) & $16(26.7)$ & $7(24.1)$ & $9(29.0)$ \\
\hline TCR, n (\%) & $\mathrm{I}(\mathrm{I} .7)$ & $0(0)$ & $\mathrm{I}(3.2)$ \\
\hline
\end{tabular}

Abbreviations: GSP, gelatin sponge particle; PGP, porous gelatin particle; UAE, uterine artery embolization; OCs, oral contraceptives; GnRH, gonadotropin-releasing hormone; TCR, transcervical resection. 
Table 2 Clinical outcomes

\begin{tabular}{|c|c|c|}
\hline Symptoms & $\begin{array}{l}3 \text { months } \\
\left(\mathrm{N}=58^{\mathrm{a}}\right), \mathrm{n}(\%)\end{array}$ & $\begin{array}{l}\text { I } 2 \text { months } \\
\left(\mathrm{N}=56^{\mathrm{b}}\right), \mathrm{n}(\%)\end{array}$ \\
\hline \multicolumn{3}{|l|}{ Menorrhagia } \\
\hline Greatly improved & II (19.0) & $20(35.7)$ \\
\hline Moderately improved & $20(34.5)$ & $21(37.5)$ \\
\hline Slightly improved & $12(20.7)$ & $8(14.3)$ \\
\hline Unchanged & $6(10.3)$ & $\mathrm{I}(\mathrm{I} .8)$ \\
\hline Worsened & $\mathrm{I}(\mathrm{I} .7)$ & $0(0.0)$ \\
\hline Previously absent & $5(8.6)$ & $4(7.1)$ \\
\hline NA & $3(5.2)$ & $2(3.6)$ \\
\hline \multicolumn{3}{|l|}{ Bulk-related symptoms } \\
\hline Greatly improved & $13(22.4)$ & $15(26.8)$ \\
\hline Moderately improved & $17(29.3)$ & $25(44.6)$ \\
\hline Slightly improved & $8(13.8)$ & $5(8.9)$ \\
\hline Unchanged & II (19.0) & $2(3.6)$ \\
\hline Worsened & $0(0.0)$ & $0(0.0)$ \\
\hline Previously absent & $6(10.3)$ & $8(14.3)$ \\
\hline NA & $3(5.2)$ & $\mathrm{I}(\mathrm{I} .8)$ \\
\hline \multicolumn{3}{|l|}{ General conditions } \\
\hline Greatly improved & I5 (25.9) & $21(37.5)$ \\
\hline Moderately improved & $24(41.4)$ & $22(39.2)$ \\
\hline Slightly improved & II (19.0) & $10(17.9)$ \\
\hline Unchanged & $5(8.6)$ & I (I.8) \\
\hline Worsened & $0(0.0)$ & $0(0.0)$ \\
\hline NA & $3(5.2)$ & $2(3.6)$ \\
\hline \multicolumn{3}{|l|}{ Satisfaction } \\
\hline Greatly satisfied & $21(36.2)$ & $31(55.4)$ \\
\hline Moderately satisfied & $25(43.1)$ & $19(33.9)$ \\
\hline Slightly satisfied & $8(13.8)$ & $4(7.1)$ \\
\hline Not satisfied & I (I.7) & $0(0.0)$ \\
\hline Dissatisfied & $0(0.0)$ & $\mathrm{I}(\mathrm{I} .8)$ \\
\hline NA & $3(5.2)$ & $\mathrm{I}(\mathrm{I} .8)$ \\
\hline \multicolumn{3}{|l|}{ Recommend to friends } \\
\hline Yes & $37(63.8)$ & $37(66.1)$ \\
\hline Neither & $18(31.0)$ & $18(32.1)$ \\
\hline No & $0(0.0)$ & I (I.8) \\
\hline NA & $3(5.2)$ & $0(0.0)$ \\
\hline
\end{tabular}

Notes: ane opted for hysterectomy (I month), and one lost to follow-up

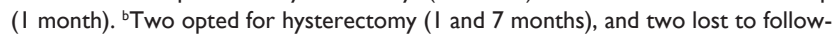
up ( 1 and 7 months).

Abbreviation: NA, not applicable.

for two patients who underwent hysterectomy. The results are summarized in Table 2. Excluding the four patients who had no menorrhagia, 49 of 50 (98.0\%) women observed an improvement in their menorrhagia 12 months after treatment, and notably, 41 (82.0\%) women noted a great-tomoderate improvement. Excluding the eight patients who did not present any bulk-related symptoms, 45 of 47 (95.7\%) women showed an improvement in bulk-related symptoms at 12 months of follow-up, while 40 (85.1\%) women noted a great-to-moderate improvement. Fifty-four of 55 (98.2\%) women were satisfied with the procedure, and 31 (56.4\%) showed great satisfaction. Volume reduction of the dominant fibroid was assessed by MRI. At 3 and 12 months, the
Table 3 Magnetic resonance imaging findings

\begin{tabular}{llll}
\hline Variable & $\begin{array}{l}\text { Pre-UAE } \\
(\mathbf{n}=6 \mathbf{0})\end{array}$ & $\begin{array}{l}\mathbf{3} \text { months } \\
(\mathbf{n}=\mathbf{5} \text { I) }\end{array}$ & $\begin{array}{l}\text { I2 months } \\
(\mathbf{n}=\mathbf{5 7})\end{array}$ \\
\hline Dominant fibroid volume, & 214.6 & 138.8 & 114.4 \\
$\mathrm{~mL}, \%(95 \% \mathrm{Cl})$ & $(28.3-5,026.5)$ & $(2.6-696.6)$ & $(0-742.7)$ \\
Reduction from baseline, & & 33.4 & 47.8 \\
$\%(95 \% \mathrm{Cl})$ & & $(24.9-4 \mathrm{I} . \mathrm{I})$ & $(39.2-55.8)$ \\
P-value from pre-UAE & & 0.0476 & 0.0148 \\
\hline
\end{tabular}

Abbreviations: $\mathrm{Cl}$, confidence interval; UAE, uterine artery embolization.

dominant fibroid volume was significantly decreased by $33.4 \%$ (95\% confidence interval [CI]: 24.9-41.1, $P=0.0476$ ) and $48.4 \%$ (95\% CI: 40.7-56.1, $P=0.0148$ ), respectively (Table 3). Among the patients who underwent UAE with gelatin sponge particles, the volume was reduced by $32.2 \%$ (95\% CI: $22.8-43.3)$ and $47.1 \%$ (95\% CI: 36.1-58.1) at 3 and 12 months, while among those with PGP, the volume was reduced by $35.1 \%$ (95\% CI: $26.2-44.0)$ and $50.0 \%$ (95\% CI: 41.5-58.5) at 3 and 12 months, respectively (data not shown). There were no significant differences as for the treatment effect between the embolic agents used in this study.

\section{Complications}

Ten patients $(16.7 \%)$ required further interventions during the follow-up period (Table 4). One patient (1.7\%) experienced deep venous thrombosis. Five patients $(8.3 \%)$ showed infection including two patients with fibroid passage, one with tubo-ovarian abscess, one with tubo-ovarian abscess and fibroid passage, and one with endometritis. Two patients experienced fibroid passages in the absence of infection, and two other patients required reintervention due to fibroid regrowth and recurrence of symptoms. In patient 1, deep venous thrombosis was unexpectedly detected by MRI at 1-month follow-up after UAE, and anticoagulation therapy was performed for 7 days. Patient 2 experienced the recurrence of menorrhagia and underwent myomectomy at 19 months after the UAE procedure. Patient 3 experienced the recurrence of menorrhagia 34 months after the UAE, while her fibroids were kept infarcted. Since she was 50 years of age at the time of recurrence, she was treated with gonadotropin-releasing hormone agonist for 6 months until menopause. Two patients with fibroid passage in the absence of infection (patients 4 and 5) underwent transvaginal resection of the extruding fibroid at an outpatient clinic 1 and 1.5 months after the UAE, respectively. Two patients with infectious fibroid passage (patients 6 and 7) underwent transvaginal and hysteroscopic resection of the extruding fibroids, respectively, accompanied by intravenous antibiotic treatment. Patient 8 presented with 
Table 4 Patients requiring further intervention due to complications or recurrence

\begin{tabular}{llll}
\hline Patient & Reason for intervention & Interval $^{\mathbf{a}}$ & Intervention $^{\text {(n) }}$ \\
\hline 1 & Deep venous thrombosis & $\mathrm{I}$ & Anticoagulation \\
2 & Fibroid regrowth & 24 & Myomectomy \\
3 & Symptom recurrence & 34 & GnRH agonist \\
4 & Fibroid passage & $\mathrm{I}$ & Transvaginal resection \\
5 & Fibroid passage & 1.5 & Transvaginal resection \\
6 & Infectious fibroid passage & $\mathrm{I}$ & Transvaginal resection, antibiotics \\
7 & Infectious fibroid passage & 7 & Hysteroscopic resection, antibiotics \\
8 & Endometritis & $\mathrm{I}$ & Hysterectomy \\
9 & Tubo-ovarian abscess and fibroid passage & 6 & Drainage, hysterectomy \\
10 & Tubo-ovarian abscess & 4 & Percutaneous drainage, antibiotics \\
\hline
\end{tabular}

Notes: anterval months from uterine artery embolization. 'Includes left salpingo-oophorectomy for firmly adhering the uterus. Includes right salpingo-oophorectomy for tubo-ovarian abscess.

Abbreviation: $\mathrm{GnRH}$, gonadotropin-releasing hormone.

fever and lower abdominal cramping 48 days after the UAE. She was admitted and initially managed conservatively with intravenous antibiotics (ampicillin-sulbactam and clindamycin). Despite 7 days of antibiotic treatment, she developed uncontrollable lower abdominal pain and decided to undergo hysterectomy. Histopathological examination confirmed an endometritis with left pyosalpinx. She was discharged on postoperative day 10 uneventfully. There were two patients who presented with tubo-ovarian abscess after the UAE as previously reported. ${ }^{12}$ Briefly, patient 9 presented with severe abdominal pain and cramping 6 months after UAE. Pelvic computed tomography revealed a bulky necrotic-appearing fibroid and a thick-walled multilocular right adnexal mass that measured $12.5 \times 9.5 \mathrm{~cm}$, suggestive of an abscess. Her blood culture was positive for Bacteroides fragilis infection. Although conservative treatments including intravenous antibiotics and percutaneous drainage were attempted, she finally required total abdominal hysterectomy and right salpingo-oophorectomy. The histopathological examination confirmed a tubo-ovarian abscess of the right fallopian tube and ovary and leiomyoma of the uterine corpus with necrosis. The patient was discharged in good condition on postoperative day 14 . Patient 10 presented with a 2-day history of right lower abdominal pain and fever 5 months after UAE. Pelvic computed tomography revealed an enlarged right adnexa that measured $7 \mathrm{~cm}$ and wall thickening of the fallopian tube, suggestive of a tubo-ovarian abscess. Under ultrasonography guidance, a percutaneous drainage catheter was placed into the abscess. Streptococcus agalactiae was identified in the brown serous drainage fluid. She was treated with intravenous ampicillin, gentamycin, and clindamycin, and then transitioned to oral sitafloxacin. On hospital day 20, the drainage catheter was removed, and the patient was discharged in good condition.

\section{Discussion}

There have been few studies on use of gelatin sponge as an embolic agent for UAE. In the majority of studies regarding UAE for symptomatic fibroids, other embolic agents including TAGMs, spherical PVA, and nPVA have been employed. Herein, we report our experience in 60 patients using gelatin sponge particles or PGP and show a high clinical success rate of $98.0 \%$ (49 of 50 patients) with improvement in menorrhagia, $95.7 \%$ (45 of 47 patients) with improvement in bulk-related symptoms, $98.2 \%$ with increased satisfaction (54 of 55 patients), and $47.8 \%$ (95\% CI: $39.2-55.8$ ) with good fibroid volume reduction 12 months after the procedure. These symptom-related improvement rates as well as the rate of volume reduction of the dominant fibroid were comparable to those of previous reports using gelatin sponge as summarized in Table $5 .^{8,13-16} \mathrm{In}$ these reports, the menorrhagia symptoms improved in $89.5 \%$ (95\% CI: $76.1 \%-100 \%$ ) of the patients, and the dominant fibroid volume was reduced by $65.1 \%$ (95\% CI: 57.7\%-72.5\%) 12 months after the procedure.

Gelatin sponge, a water-insoluble, hemostatic material prepared from purified gelatin (a nonantigenic protein), has been used for embolization for over 30 years as a biodegradable, intravascular embolic agent in interventional radiology with specific use as a temporary embolic agent in hemorrhage. ${ }^{6,14}$ Since TAGMs, the main embolic agent used in Western countries, were not approved in Japan until 2014, gelatin sponge has been unavoidably used for UAE in Japan. The absorbable nature of gelatin sponge indicates that arteries that were previously occluded with a gelatin sponge could be recanalized within several weeks. However, recanalization has been shown to cause no disadvantage for embolized fibroids, as follow-up enhanced MRI revealed that most fibroids were infarcted and decreased in volume 
Table 5 Outcomes of uterine artery embolization using gelatin sponge as an embolic agent for symptomatic uterine fibroids

\begin{tabular}{|c|c|c|c|c|c|}
\hline Study & Study design & $\begin{array}{l}\text { Number } \\
\text { of patients }\end{array}$ & $\begin{array}{l}\text { Follow-up } \\
\text { (months) }\end{array}$ & Symptom improvement (\%) & $\begin{array}{l}\text { Dominant fibroid } \\
\text { volume reduction (\%) }\end{array}$ \\
\hline Katsumori et $\mathrm{al}^{8}$ & Prospective & 25 & 12 & $\begin{array}{l}\text { Menorrhagia, 70; bulk, 90; pain, } 100 \\
\text { (at } 12 \text { months) }\end{array}$ & $\begin{array}{l}49.0 \text { (at } 4 \text { months), } 61.2 \\
\text { (at } 12 \text { months) }\end{array}$ \\
\hline Katsumori et $\mathrm{al}^{13}$ & Prospective & 96 & 37.4 & $\begin{array}{l}\text { Symptom control, } 96.9 \text { (at } 12 \text { months), } 89.5 \\
\text { (at } 60 \text { months) }\end{array}$ & NA \\
\hline Sone et $\mathrm{al}^{14}$ & $\begin{array}{l}\text { Prospective } \\
\text { Phase I/II }\end{array}$ & 33 & 33.4 & $\begin{array}{l}\text { Menorrhagia, 90; bulk, 76; pain, } 96 \\
\text { (at } 12 \text { months) }\end{array}$ & 61.4 (at 12 months) \\
\hline Huang et $\mathrm{al}^{16}$ & Prospective & 40 & 8.1 & Menorrhagia, 83; pain, 77 (at 8 months) & 54.9 (at 8 months) \\
\hline Song et $\mathrm{al}^{15}$ & Prospective & 30 & 12.9 & Menorrhagia, 100; bulk, 92 (at 12 months) & $\begin{array}{l}56.2 \text { (at } 3 \text { months), } 72.6 \\
\text { (at } 12 \text { months) }\end{array}$ \\
\hline Present study & Retrospective & 60 & 25.2 & Menorrhagia, 98; bulk, 96 (at 12 months) & 47.8 (at 12 months) \\
\hline
\end{tabular}

Abbreviation: NA, not applicable.

without any regrowth, while the blood flow of the intact uterine myometrium was preserved..$^{17}$ Moreover, gelatin sponge is much cheaper and more cost-effective than other embolic agents, which might reduce the total cost of UAE procedures. In contrast, the disadvantages of gelatin sponge include its tedious preparation and the variable particle sizes obtained. Gelatin sponge particles are often hand-prepared and cut from sheets of gelatin sponge to make a slurry. PGPs are roughly calibrated agents and have some degree of variability in size distribution compared with other embolic agents. ${ }^{6}$ Further, unexpected smaller PGP fragments are present after passing thorough the microcatheter, ${ }^{6}$ which could lead to nontargeted ovarian embolization and uterine necrosis. This might result in a more distal occlusion, potentially increasing the risk of end-organ infarction. ${ }^{18,19}$

While several studies have compared various embolic agents for $\mathrm{UAE},{ }^{20-24}$ to our knowledge, only one recent study compared gelatin sponge particles with another embolic agent. ${ }^{25}$ In their report, gelatin sponge particles were not shown to be inferior to nPVA particles in terms of improvement of mean bleeding score and rate of volume reduction of the dominant fibroid $(60.2 \% \pm 18.1 \%)$ at the 3 -month follow-up after UAE, ${ }^{25}$ while only $33.4 \%$ of the size reduction in the dominant fibroid was seen in our study. However, this study was conducted at a single institution with a relatively small number of patients and short follow-up period. Further research should be encouraged to standardize reporting of technical and clinical outcomes to guide practice.

Regarding adverse events, no angiography-related complications occurred, including allergy to iodinated contrast media, hemorrhage at puncture site, or vascular injury, which have been reported in $1 \%-3 \%$ of cases. ${ }^{3,26}$ Postprocedural complications including fibroid passage, infection, permanent amenorrhea, and deep venous thrombosis were observed in 11 (18.3\%) of 60 patients, four of whom had multiple complications. Three of five fibroid passages occurred 1-2 months after UAE, which was consistent with a previous report describing the greatest frequency of fibroid passages within 3 months. ${ }^{27}$ The remaining two occurred after 6 and 7 months, respectively, which suggests that fibroid passage can happen at any time after UAE and patients should be warned of this late complication. ${ }^{28}$ Of the five infective complications, three $(60 \%)$ exhibited fibroid passages implying that fibroid passage is part of a spectrum of infections in UAE, as previously reported. ${ }^{27}$ Two patients with a history of previous surgery experienced a tubo-ovarian abscess. UAE likely causes ischemia of the fallopian tube that increases the propensity of microbes to ascend the tract easily and cause endothelial damage, leading to a tubo-ovarian abscess. ${ }^{12}$ The incidence of infectious complications in the present study was $8.3 \%$, which was a little higher compared to the comprehensive review report $(1 \%-3 \%){ }^{3}$ Since the use of gelatin sponge agents has been reported to be associated with infectious complications, this high incidence might not be a negligible disadvantage to use gelatin sponge particles or PGP in the clinical setting. ${ }^{29}$ The incidence of permanent amenorrhea after UAE is highly age-dependent, and the reported occurrence of permanent amenorrhea in women whose age is $\geq 45$ years is $20 \%-40 \%$, while at $<45$ years of age, the occurrence is $0 \%-3 \%{ }^{3}$ In the present study, of the 34 patients aged $\geq 45$ years, four (11.8\%) experienced permanent amenorrhea, which was not experienced in any of the 26 women $<45$ years of age. When addressing UAE as an attractive alternative procedure to surgery, further intervention rates must be taken into account. Cumulative rate free from further intervention for either recurrence or complications was $83.7 \%$ at 2 years, and $78.4 \%$ at 5 years in our study, which appears similar to rates from previous studies that have reported that over a quarter of women required further interventions during a long-term follow-up (5 years) after UAE. ${ }^{30-33}$ 
There are several limitations to this study. First, this was a nonrandomized retrospective study conducted at a single institution with a limited follow-up period. Second, we assessed the efficacy of UAE with an original questionnaire and were not able to measure established quality-of-life (QOL) scores such as the Uterine Fibroid Symptom QOL questionnaire, Short Form-12, Short Form-36, or the EuroQOL, which may provide a more positive interpretation in the setting of end points for UAE trials.

In conclusion, despite these limitations, our study provides further data in support of greater improvement of fibroid-related symptoms observed in women undergoing UAE with gelatin sponge particles and PGP. To establish the clinical position of these embolic agents on UAE, randomized controlled trials comparing other embolic agents and evaluation of costs are warranted.

\section{Acknowledgments}

The authors thank Mami Morikawa for her secretarial assistance. There is no source of financial grant or other funding to be acknowledged.

\section{Disclosure}

The authors report no conflicts of interest in this work.

\section{References}

1. Baird DD, Dunson DB, Hill MC, Cousins D, Schectman JM. High cumulative incidence of uterine leiomyoma in black and white women: ultrasound evidence. Am J Obstet Gynecol. 2003;188(1): 100-107.

2. Payne JF, Haney AF. Serious complications of uterine artery embolization for conservative treatment of fibroids. Fertil Steril. 2003;79(1): 128-131.

3. Dariushnia SR, Nikolic B, Stokes LS, Spies JB; Society of Interventional Radiology Standards of Practice Committee. Quality improvement guidelines for uterine artery embolization for symptomatic leiomyomata. J Vasc Interv Radiol. 2014;25(11):1737-1747.

4. Spies JB. Current role of uterine artery embolization in the management of uterine fibroids. Clin Obstet Gynecol. 2016;59(1):93-102.

5. American College of Obstetricians and Gynecologists. ACOG practice bulletin. Alternatives to hysterectomy in the management of leiomyomas. Obstet Gynecol. 2008;112(2 Pt 1):387-400.

6. Das R, Champaneria R, Daniels JP, Belli AM. Comparison of embolic agents used in uterine artery embolisation: a systematic review and meta-analysis. Cardiovasc Intervent Radiol. 2014;37(5):1179-1190.

7. Worthington-Kirsch RL, Siskin GP, Hegener P, Chesnick R. Comparison of the efficacy of the embolic agents acrylamido polyvinyl alcohol microspheres and tris-acryl gelatin microspheres for uterine artery embolization for leiomyomas: a prospective randomized controlled trial. Cardiovasc Intervent Radiol. 2011;34(3):493-501.

8. Katsumori T, Kasahara T, Oda M, Kotani T. Initial experience of uterine fibroid embolization using porous gelatin sponge particles. Cardiovasc Intervent Radiol. 2011;34(3):513-521.

9. Katsumori T, Kasahara T, Tsuchida Y, Nara Y. MR venography of deep veins: changes with uterine fibroid embolization. Cardiovasc Intervent Radiol. 2009;32(2):284-288.
10. Kojima T, Taki Y, Fujisawa H, Koyama K. Leiomyoma treatment by uterine artery embolization using gelatin sponge prepared by the pumping method. Exp Ther Med. 2012;4(5):781-784.

11. Janik P, Briand P, Hartmann NR. The effect of estrone-progesterone treatment on cell proliferation kinetics of hormone-dependent GR mouse mammary tumors. Cancer Res. 1975;35(12):3698-3704.

12. Toda A, Sawada K, Osuga K, et al. Tubo-ovarian abscess after uterine artery embolization for uterine fibroid. Gynecol Obstet (Sunnyvale). 2015;5:306.

13. Katsumori T, Kasahara T, Akazawa K. Long-term outcomes of uterine artery embolization using gelatin sponge particles alone for symptomatic fibroids. AJR Am J Roentgenol. 2006;186(3):848-854.

14. Sone M, Arai Y, Shimizu T, et al. Phase I/II multiinstitutional study of uterine artery embolization with gelatin sponge for symptomatic uterine leiomyomata: Japan Interventional Radiology in Oncology Study Group study. J Vasc Interv Radiol. 2010;21:1665-1671.

15. Song YG, Woo YJ, Kim CW. Uterine artery embolization using progressively larger calibrated gelatin sponge particles. Minim Invasive Ther Allied Technol. 2016;25(1):35-42.

16. Huang LY, Cheng YF, Chang HW, et al. Quantified short-term outcome of uterine artery embolization with gelatin sponge particles and lipiodol for symptomatic myoma. Fertil Steril. 2004;81(5):1375-1382.

17. Katsumori T, Nakajima K, Tokuhiro M. Gadolinium-enhanced MR imaging in the evaluation of uterine fibroids treated with uterine artery embolization. AJR Am J Roentgenol. 2001;177(2):303-307.

18. Siskin GP, Englander M, Stainken BF, Ahn J, Dowling K, Dolen EG. Embolic agents used for uterine fibroid embolization. AJR Am J Roentgenol. 2000;175(3):767-773.

19. Pelage JP. Polyvinyl alcohol particles versus tris-acryl gelatin microspheres for uterine artery embolization for leiomyomas. J Vasc Interv Radiol. 2004;15:789-791.

20. Spies JB, Allison S, Flick P, et al. Spherical polyvinyl alcohol versus tris-acryl gelatin microspheres for uterine artery embolization for leiomyomas: results of a limited randomized comparative study. J Vasc Interv Radiol. 2005;16(11):1431-1437.

21. Spies JB, Allison S, Flick P, et al. Polyvinyl alcohol particles and tris-acryl gelatin microspheres for uterine artery embolization for leiomyomas: results of a randomized comparative study. J Vasc Interv Radiol. 2004;15(8):793-800.

22. Galvez JA, McCarthy S, Weinreb J, et al. Comparison of MRI outcomes of uterine artery embolization for uterine leiomyoma using tris-acryl gelatin microspheres, polyvinyl alcohol spheres, and polyvinyl alcohol particles. J Comput Assist Tomogr. 2008;32(3):356-361.

23. Rasuli P, Hammond I, Al-Mutairi B, et al. Spherical versus conventional polyvinyl alcohol particles for uterine artery embolization. J Vasc Interv Radiol. 2008;19(1):42-46.

24. Siskin GP, Beck A, Schuster M, Mandato K, Englander M, Herr A. Leiomyoma infarction after uterine artery embolization: a prospective randomized study comparing tris-acryl gelatin microspheres versus polyvinyl alcohol microspheres. J Vasc Interv Radiol. 2008;19(1): $58-65$.

25. Song YG, Jang H, Park KD, Kim MD, Kim CW. Non spherical polyvinyl alcohol versus gelatin sponge particles for uterine artery embolization for symptomatic fibroids. Minim Invasive Ther Allied Technol. 2013; 22(6):364-371.

26. Spies JB, Spector A, Roth AR, Baker CM, Mauro L, Murphy-Skrynarz K. Complications after uterine artery embolization for leiomyomas. Obstet Gynecol. 2002;100(5 Pt 1):873-880.

27. Shlansky-Goldberg RD, Coryell L, Stavropoulos SW, et al. Outcomes following fibroid expulsion after uterine artery embolization. J Vasc Interv Radiol. 2011;22(11):1586-1593.

28. Marret H, Keris Yle B, Acker O, Cottier JP, Herbreteau D. Late leiomyoma expulsion after uterine artery embolization. $J$ Vasc Interv Radiol. 2004;15(12):1483-1485.

29. Abada HT, Golzarian J. Gelatine sponge particles: handling characteristics for endovascular use. Tech Vasc Interv Radiol. 2007;10(4): $257-260$. 
30. van der Kooij SM, Hehenkamp WJ, Volkers NA, Birnie E, Ankum WM, Reekers JA. Uterine artery embolization vs hysterectomy in the treatment of symptomatic uterine fibroids: 5-year outcome from the randomized EMMY trial. Am J Obstet Gynecol. 2010;203:105.e1-105.e13.

31. Moss JG, Cooper KG, Khaund A, et al. Randomised comparison of uterine artery embolisation (UAE) with surgical treatment in patients with symptomatic uterine fibroids (REST trial): 5-year results. BJOG. 2011;118(8):936-944.
32. Hamoda H, Pepas L, Tasker F, Reidy J, Khalaf Y. Intermediate and long-term outcomes following uterine artery fibroid embolization. Eur J Obstet Gynecol Reprod Biol. 2015;191:33-38.

33. Duvnjak S, Ravn P, Green A, Andersen PE. Clinical long-term outcome and reintervention rate after uterine fibroid embolization with nonspherical versus spherical polyvinyl alcohol particles. Cardiovasc Intervent Radiol. 2016;39(2):204-209.

\section{Publish your work in this journal}

The International Journal of Women's Health is an international, peerreviewed open-access journal publishing original research, reports, editorials, reviews and commentaries on all aspects of women's healthcare including gynecology, obstetrics, and breast cancer. The manuscript management system is completely online and includes a very quick and fair peer-review system, which is all easy to use. Visit http://www.dovepress.com/testimonials.php to read real quotes from published authors.

Submit your manuscript here: http://www.dovepress.com/international-journal-of-womens-health-journal 